\title{
LETTER FROM THE EDITOR
}

\section{No longer free for all}

$\mathrm{S}$ ince the Canadian Medical Association Journal went online in the mid-1990s, the Canadian Medical Association has provided unrestricted access to all CMAJ content. However, given the changing economic times, we can no longer afford to do so. As of January 2010, some content will be restricted to CMA members, subscribers and pay-per-view readers.

This was a difficult decision, because we believe that scientific information should be accessible to all. The CMA, our editorial team and many past editors of $C M A J$ have strongly endorsed open access.

Online, CMAJ is publishing more content, with new articles posted weekly and news pieces added almost daily. ${ }^{1}$ However, we have experienced a perfect storm involving rising editorial costs to handle the extra content, and dramatic decreases in advertising. Processes such as peer review and the editing of manuscripts require expertise and time to ensure that scientific articles are well reported and ․ reliable. $^{2}$

Ideally, medical information that saves lives and reduces harm should not be up for sale - at least not to the end-user. Such material should be treated as a public good and paid for by the public, which is why research will remain free of charge. Editorials, news, clinical images, abstracts and previously published articles will also remain accessible to all readers. Access to reviews, analysis, practice, commentaries, humanities and supplements will be restricted to members of CMA, although these items will become free of charge 12 months after publication.

As part of our commitment to the dissemination of knowledge, readers in most developing countries will be offered free access through the Health InterNetwork Access to Research Initiative (HINARI) of the World Health Organization and through Access to Global Online Research in Agriculture (AGORA). We hope these steps will meet the needs of many of our international readers.

Changing times call for changing approaches. While our publishing model is different, our content will continue to be relevant and topical, from research to clinical practice to policy-oriented editorials. We remain committed to publishing medical knowledge that matters.

\section{Paul C. Hébert MD MHSc \\ Editor-in-Chief \\ CMAJ}

\section{REFERENCES}

1. Hébert PC. Letter from the Editor: CMAJ in changing times. CMAJ 2009;181: 125.

2. Sox HC. Medical journal editing: Who shall pay? [editorial]. Ann Intern Med 2009;151:68-9. 